\title{
Diagnóstico ambiental da bacia hidrográfica do Rio Atibaia, SP, utilizando ferramentas de geoprocessamento
}

\author{
Guilherme Lucas de Laurentis ${ }^{1}$ \\ Antônio Carlos Demanboro ${ }^{1}$ \\ Thiago Borges Conforti ${ }^{2}$ \\ Samuel Fernando Adami ${ }^{3}$ \\ Sueli do Carmo Bettine ${ }^{1}$
}

\section{${ }^{1}$ Pontifícia Universidade Católica de Campinas - PUCCAMP \\ Rodovia D. Pedro I, km 136 - Parque das Universidades - 13086-900 - Campinas - SP, Brasil \\ \{guilherme.laurentis, demanboro, subettine\}@puc-campinas.edu.br}

\author{
${ }^{2}$ Fundação Florestal - FF / SMA-SP \\ Rua do Horto, 931 - São Paulo SP \\ thiagobc@fflorestal.sp.gov.br
}

\author{
${ }^{3}$ Instituto Agronômico - IAC \\ Av. Barão de Itapura, n.1481, Botafogo - 13020-902 - Campinas- SP \\ samuel@iac.sp.gov.br
}

\begin{abstract}
In this paper it is done the environmental diagnosis of the Atibaia river watershed. Were generated maps in a GIS environment for themes like the main types of soils, the altitude and declivity, water resources situation, land-use, protected areas, the potential fragility and the environmental fragility in the basin. The results show that, though the area is not fully urbanized $(11,97 \%)$ and there are a relatively high number of areas covered by forest $(27,54 \%)$, it can be said that the watershed is under a process of environmental degradation. During the diagnosis, were identified $1.128,86 \mathrm{~km}^{2}$ of the total area that has potential fragility graded from strong to very strong, while $447,64 \mathrm{~km}^{2}$ has environmental fragility in the same grades. This numbers, allied to the other informations achieved, suggest that the first measures of restoration of degraded land in the watershed need to be focused in the recompostion of vegetation of the Permanent Preservation Areas and the reduction of the instability of areas with strong to very strong environmental fragility, through afforestation.
\end{abstract}

Palavras-chave: ecodinâmica, fragilidade ambiental, qualidade ambiental, SIG.

\section{Introdução}

Nos últimos anos, têm sido observados efeitos adversos na paisagem de grande parte das cidades brasileiras, como conseqüência da ocupação humana desordenada. Tais efeitos são diretamente influenciados por fatores como a especulação imobiliária, o crescimento populacional e o desenvolvimento de atividades econômicas, que acabam por favorecer a expansão da mancha urbana e aumentam a intervenção antrópica em ambientes naturais. Essa interferência promove alterações que podem ocasionar danos ambientas de grande magnitude. Nesses casos, deve-se adotar uma abordagem diferenciada, para que sejam corretamente compreendidas as dinâmicas dos ecossistemas e para que ações de planejamento sejam direcionadas (Santos et al., 2007).

Ganzeli (1995) relaciona o desenvolvimento dos municípios à atração de atividades altamente degradantes dos recursos hídricos. A exploração intensa e desordenada ocasiona problemas como conurbação, multiplicação das cidades-dormitório, falta de saneamento e poluição dos corpos d'água, comprometendo o abastecimento das cidades.

Como resultado dessas intervenções, observa-se impactos significativos no ecossistema local, que têm na bacia hidrográfica sua delimitação geográfica (Tundisi, 2003; CNRBMA \& SOS-MA, 2003; Coelho et al., 2005). Esses impactos, associados ao uso inadequado das 
terras, interferem diretamente na dinâmica das bacias hidrográficas, tanto do ponto de vista ecológico quanto da disponibilidade de água. São necessárias, portanto, medidas voltadas à mitigação dos impactos causados, sob gerenciamento integrado em diferentes escalas, aliada a política de conservação ambiental e de conscientização sobre o uso da água (Tundisi, 2003; Santos, 2004; Santos et al., 2007).

Portanto, deve-se buscar a compreensão da complexidade envolvida no funcionamento dos diferentes mecanismos e processos que atuam nos sistemas naturais, além da intensidade e da dinâmica das intervenções humanas. Ambientes em equilíbrio, considerados estáveis por Tricart (1977), tendem a manter características naturais, ao passo que a instabilidade começa a aumentar na medida em que o grau de intervenções antrópicas sobre os mesmos também são intensificados. Ross (1994) insere novos critérios nessa análise, como o mapeamento da fragilidade potencial (segundo condições naturais do ambiente) e da fragilidade emergente ou ambiental (resultante das intervenções antrópicas em condições de fragilidade potencial).

Assim, a realização do diagnóstico ambiental facilita essa interpretação, uma vez que possibilita a observação do meio como um todo, considerando sua composição, estrutura, processo e função no espaço, através do levantamento de dados ligados interligados de forma multidisciplinar (Santos, 2004; Ross, 2007).

A etapa de diagnóstico envolve uma série de procedimentos metodológicos, visando à obtenção de um conjunto de dados que subsidiem a análise integrada e a produção de informações. São etapas dessa fase a obtenção de dados de entrada e a análise integrada, para que posteriormente possam ser elaborados indicadores como suporte à tomada de decisão (Fidalgo, 2003; Santos, 2004). Os dados de entrada são geralmente agrupados por temas, para melhor compreensão e interpretação. Os temas escolhidos variam segundo as diretrizes e os objetivos específicos em cada caso, contabilizando aspectos físicos, biológicos, econômicos, sociais e culturais (Macedo, 1995; Santos, 2004).

Para tanto, tem-se nos Sistemas de Informações Geográficas (SIGs) uma importante ferramenta, que possibilitam o processamento dessas informações multidisciplinares de forma integrada, além de permitir o relacionamento dos dados com sua representação espaçotemporal (Bernhardsen, 1992; Longley et al., 1999; Câmara \& Queiroz, 2001).

Este trabalho realizou o diagnóstico ambiental da bacia hidrográfica do Rio Atibaia, uma das sub-bacias formadoras do Rio Piracicaba, localizada nos estados de São Paulo e Minas Gerais. Utilizou-se a abordagem ecodinâmica, aliada a um SIG como integrador das informações, para identificar o atual estágio de degradação decorrente da ocupação antrópica na bacia; tal identificação é instrumento auxiliar no direcionamento de prioridades para a melhoria da qualidade ambiental da área.

\section{Caracterização da área de estudo}

A bacia hidrográfica do Rio Atibaia localiza-se entre os paralelos $22^{\circ} 40^{\prime} \mathrm{S}$ e $23^{\circ} 20^{\prime} \mathrm{S}$ e os meridianos $47^{\circ} 20^{\prime} \mathrm{W}$ e $46^{\circ} 00^{\prime} \mathrm{W}$, com uma área de $2.816,40 \mathrm{~km}^{2}$. Estão inseridos na bacia, total ou parcialmente, 16 municípios do estado de São Paulo e um do estado de Minas Gerais. A região merece destaque, pois abriga parte da Região Metropolitana de Campinas (RMC), área com vasto e diversificado parque industrial, além de pólo tecnológico importante no cenário nacional. Segundo Duarte Neto (2005), dos 19 municípios que compõem a RMC, sete fazem uso direto ou indireto das águas da bacia do Rio Atibaia, seja para fins de captação ou para lançamento de esgoto doméstico. São eles: Americana, Campinas, Itatiba, Paulínia, Sumaré, Valinhos e Vinhedo.

$\mathrm{O}$ consumo de água na bacia é predominantemente urbano $\left(5,02 \mathrm{~m}^{3} / \mathrm{s}\right)$, seguido do uso industrial $\left(3,26 \mathrm{~m}^{3} / \mathrm{s}\right)$ e rural $\left(1,62 \mathrm{~m}^{3} / \mathrm{s}\right)$. Tem-se, no total, uma demanda estimada de 10,02 $\mathrm{m}^{3} / \mathrm{s}$ de água (IRRIGART, 2007). Além desses usos, existem na bacia dois reservatórios que 
compõem o Sistema Cantareira, responsáveis por enviar $9 \mathrm{~m}^{3} / \mathrm{s}$ de água para a RMSP, sendo 4 $\mathrm{m}^{3} / \mathrm{s}$ oriundos do Reservatório Atibainha e $5 \mathrm{~m}^{3} / \mathrm{s}$ do Reservatório Cachoeira (Whately, 2007).

A Figura 1 ilustra a localização da bacia hidrográfica do Rio Atibaia.

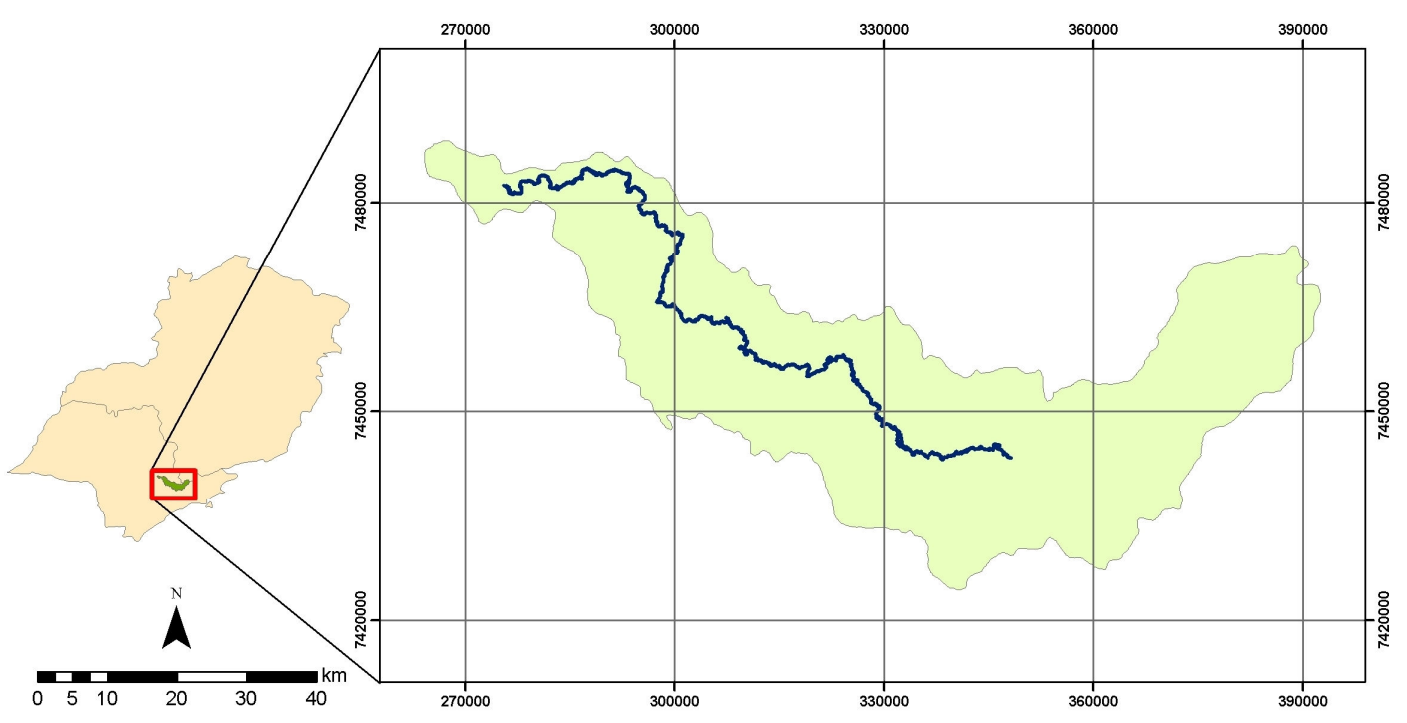

Figura 1 - Localização da área de estudo.

\section{Materiais e Métodos}

Os dados utilizados foram separados por temas, espacializados e manuseados em ambiente SIG. Para isso utilizou-se o software ILWIS 3.4, cujos procedimentos metodológicos da estruturação e da realização de cada tema são descritos na Tabela 1.

Tabela 1 - Métodos de aquisição dos dados para integração no diagnóstico.

\begin{tabular}{lll}
\hline \multicolumn{1}{c}{ Tema } & \multicolumn{1}{c}{ Descrição } & \multicolumn{1}{c}{ Fonte } \\
\hline Pedologia & Escala 1:500.000 & $\begin{array}{l}\text { Trecho paulista: Oliveira et al. (1999) } \\
\text { Trecho mineiro: IRRIGART (2004). }\end{array}$ \\
\hline $\begin{array}{l}\text { Relevo (Declividade e } \\
\text { Hipsometria) }\end{array}$ & Escala 1:50.000 & IBGE (1983). \\
\hline Rios e lagos & Escala 1:50.000 & IBGE (1983). \\
\hline Nascentes & Escala 1:50.000 & Elaborado pelo autor. \\
\hline $\begin{array}{l}\text { Pontos de captação e } \\
\text { lançamento }\end{array}$ & $\begin{array}{l}\text { Captação (superficial e subterrânea) } \\
\text { e lançamento (esgoto doméstico) }\end{array}$ & IRRIGART (2004). \\
\hline $\begin{array}{l}\text { Uso das terras } \\
\text { Unidades de Conservação } \\
\text { (UCs) }\end{array}$ & $\begin{array}{l}\text { UCs de Proteção integral e de } \\
\text { Uso Sustentável }\end{array}$ & Elaborado pelo autor. \\
\hline $\begin{array}{l}\text { Áreas de Preservação } \\
\text { Permanente (APPs) }\end{array}$ & APPs fluviais & \begin{tabular}{l} 
Conforti et al. (2008); BRASIL (2000). \\
\hline
\end{tabular}
\end{tabular}

$\mathrm{Na}$ primeira parte do diagnóstico, foi realizado o mapeamento Ecodinâmico (Tricart, 1977; Ross, 1994), que classifica os ambientes segundo sua fragilidade (Potencial e Ambiental). Sendo assim, caracterizaram-se os ambientes quanto à sua estabilidade ou instabilidade, seja ela natural ou induzida. A Carta de Fragilidade Potencial resultou do cruzamento entre os mapas de Declividade e de Solos gerados. Considerou-se que áreas com 
baixas declividades são menos instáveis que áreas com declividade elevada, conforme a Tabela 2.

Tabela 2 - Classes de declividade e grau de dissecação.

\begin{tabular}{cc}
\hline Grau de dissecação & Declividade \\
\hline Muito fraca & Até $6 \%$ \\
Fraca & Entre $6 \%$ e $12 \%$ \\
Média & Entre $12 \%$ e $20 \%$ \\
Forte & Entre $20 \%$ e $30 \%$ \\
Muito forte & Acima de $30 \%$ \\
\hline
\end{tabular}

Fonte: Ross (1994).

Para o Mapa de Solos procedeu-se à reclassificação com base na fragilidade de cada tipo de solo frente ao escoamento superficial de águas pluviais, variando de muito fraca a muito forte. Quando se trata de uma unidade de solos composta, aquela formada por dois ou mais tipos de solos, adotou-se o grau de fragilidade do mais frágil, conforme Tabela 3.

Tabela 3 - Fragilidade dos tipos de solo encontrados na bacia.

\begin{tabular}{|c|c|}
\hline Tipo de solo & Fragilidade \\
\hline Latossolo Vermelho textura argilosa & Muito fraca \\
\hline Latossolo Vermelho-Amarelo textura argilosa + Argissolo Vermelho-Amarelo textura argilosa & Muito fraca \\
\hline Latossolo Vermelho-Amarelo textura argilosa + Cambissolo textura argilosa & Fraca \\
\hline $\begin{array}{l}\text { Argissolo Vermelho-Amarelo textura média/argilosa e argilosa }+ \text { Argissolo Vermelho textura } \\
\text { média/argilosa e argilosa }\end{array}$ & Média \\
\hline Argissolo Vermelho-Amarelo textura arenosa/média & Média \\
\hline Argissolo Vermelho-Amarelo textura arenosa/média e média/argilosa & Média \\
\hline $\begin{array}{l}\text { Argissolo Vermelho-Amarelo textura arenosa/média + Latossolo Vermelho-Amarelo textura } \\
\text { média }\end{array}$ & Média \\
\hline Argissolo Vermelho-Amarelo textura argilosa e média cascalhenta/argilosa cascalhenta & Média \\
\hline $\begin{array}{l}\text { Argissolo Vermelho-Amarelo textura argilosa e média/argilosa + Latossolo Vermelho-Amarelo } \\
\text { textura argilosa }\end{array}$ & Média \\
\hline $\begin{array}{l}\text { Argissolo Vermelho-Amarelo textura média + Argissolo Vermelho-Amarelo textura } \\
\text { arenosa/média e média }\end{array}$ & Média \\
\hline Argissolo Vermelho-Amarelo textura média/argilosa e argilosa & Forte \\
\hline Argissolo Vermelho-Amarelo textura argilosa + Cambissolo textura argilosa e média & Forte \\
\hline $\begin{array}{l}\text { Argissolo Vermelho-Amarelo textura média/argilosa e argilosa + Cambissolo textura argilosa e } \\
\text { média }\end{array}$ & Forte \\
\hline Cambissolo textura argilosa & Forte \\
\hline Cambissolo textura argilosa + Latossolo Vermelho-Amarelo textura argilosa & Forte \\
\hline Gleissolo + Argissolo Vermelho-Amarelo textura média/argilosa + Cambissolo textura argilosa & Muito Forte \\
\hline
\end{tabular}

Fonte: Adaptado de Ross (1994).

Isto permitiu a associação entre os graus de dissecação do relevo e os graus de fragilidade dos solos. Para a elaboração da tabela, nos cruzamentos entre graus diferentes de fragilidade, considerou-se dominante sempre o mais forte. 
Finalizada a Carta de Fragilidade Potencial, foi necessário reclassificar o Mapa de Uso das Terras, já que o mesmo foi determinante na geração da Carta de Fragilidade Ambiental. Ponderou-se, então, para cada tipo de uso um grau de proteção frente a movimentos degradacionais, variando desde proteção Muito Alta até Muito Baixa e Nula (Tabela 4).

Tabela 4 - Grau de proteção oferecido por cada uso da terra.

\begin{tabular}{cc}
\hline Uso & Grau de proteção \\
\hline Área urbanizada, Floresta & Muito Alta \\
Pastagem, Reflorestamento & Alta \\
Área Rural & Média \\
Solo Exposto & Muito baixa \\
Lago/Represa & Nula \\
\hline
\end{tabular}

Fonte: Adaptado de Ross (1994).

Para elaboração da Carta de Fragilidade Ambiental foram cruzados os dados de Fragilidade Potencial com o grau de proteção que cada uso oferece ao solo, decorrente da relação entre a Fragilidade Potencial e a proteção que a área recebe. Para isso elaborou-se outra tabela bidimensional, ainda segundo os critérios de dominância do mais forte.

\section{Resultados e discussão}

As informações obtidas para cada tema subsidiaram a elaboração de mapas temáticos e de síntese, posteriormente integrados em ambiente SIG. A integração dessas informações facilita a análise dos dados e favorece a continuidade do diagnóstico.

Em relação aos tipos de solos, observa-se a predominância dos tipos Latossolo VermelhoAmarelo e Argissolo Vermelho-Amarelo, conforme a Tabela 5. Observou-se também que, em $80 \%$ da área total da bacia, são encontrados solos do tipo Argissolo Vermelho-Amarelo.

Tabela 5 - Ocorrência dos principais solos por tipo na bacia.

\begin{tabular}{lcc}
\hline \multicolumn{1}{c}{ Tipo de solo } & Área $\mathbf{( k m}^{\mathbf{2}} \mathbf{)}$ & $\mathbf{\%}$ \\
\hline $\begin{array}{l}\text { Latossolo Vermelho-Amarelo textura argilosa + Argissolo Vermelho-Amarelo } \\
\text { textura argilosa }\end{array}$ & 969,98 & 34,44 \\
Argissolo Vermelho-Amarelo textura média/argilosa e argilosa + Cambissolo & 364,58 & 12,94 \\
textura argiolsa e média & 280,96 & 9,98 \\
Argissolo Vermelho-Amarelo textura média/argilosa e argilosa & 258,64 & 9,18 \\
Argissolo Vermelho-Amarelo textura argilosa e média cascalhenta/argilosa & 255,39 & 9,07 \\
cascalhenta & 686,85 & 24,39 \\
Latossolo Vermelho textura argilosa & & \\
Outros (inclui solo aluvial)
\end{tabular}

Fonte: Elaborado pelo autor.

Com relação aos valores hipsométricos, predominam na bacia áreas pouco íngremes, representando $57 \%$ da área total, o que correspondente a $1.604,97 \mathrm{~km}^{2}$. Áreas muito íngremes, com declividade superior a $30 \%$, ocorrem em $392,40 \mathrm{~km}^{2}$, localizadas predominantemente no trecho de montante da bacia, na porção montanhosa.

No tocante ao recurso água, foram mapeados 86 pontos de captação de água na bacia, sendo 69 de águas subterrâneas e 17 de águas superficiais, ao passo que os lançamentos de esgoto são representados por 14 pontos (IRRIGART, 2004). Entre os municípios que captam água na bacia estão Atibaia, Bom Jesus dos Perdões, Campinas, Itatiba, Jarinú, Jundiaí, Nazaré Paulista, Paulínia, Piracaia e Valinhos, além de indústrias dos segmentos químico, petroquímico e celulose. Também foram identificadas 6.158 nascentes na bacia, segundo a escala de mapeamento de drenagem utilizada. 
O uso das terras que predomina na bacia é o uso rural, que ocorre em mais de $50 \%$ do território, se estendendo por $1.422,95 \mathrm{~km}^{2}$. A cobertura vegetal, representada por fragmentos de floresta nativa, matas ciliares e capoeiras, ocupa $27,54 \%$ do território. Áreas urbanizadas e industrializadas totalizam aproximadamente $12 \%$. Os valores encontrados para os demais usos podem ser observados na Tabela 6.

Tabela 6 - Área correspondente a cada tipo de uso da terra na bacia.

\begin{tabular}{ccc}
\hline Uso & Área $\left.\mathbf{( k m}^{\mathbf{2}}\right)$ & $\mathbf{\%}$ \\
\hline Rural & $1.422,95$ & 50,52 \\
Floresta & 775,61 & 27,54 \\
Urbanizado & 337,18 & 11,97 \\
Reflorestamento/silvicultura & 153,40 & 5,45 \\
Pastagem & 86,94 & 3,09 \\
Lago/represa & 33,67 & 1,20 \\
Solo exposto & 6,77 & 0,24 \\
\hline
\end{tabular}

Fonte: Elaborado pelo autor.

Apesar do pequeno percentual de áreas urbanizadas (11,97\%), a bacia apresenta um alto grau de intervenção antrópica devido à predominância dos usos agrícolas (50,52\%). Destacase, ainda, a quantidade de remanescentes florestais, que totalizam $27,5 \%$ da área total, devido principalmente às áreas de morros na região das cabeceiras onde é mais difícil a ocupação, sendo em geral mantida a vegetação natural.

Para a proteção de parte dessa vegetação nativa remanescente foram estabelecidas na bacia sete UCs, sendo uma de Proteção Integral e seis de Uso Sustentável, totalizando 1.625 $\mathrm{km}^{2}$ de áreas protegidas por UCs que representa 57,7\% do território. A única UC de Proteção Integral é a Estação Ecológica Estadual de Valinhos $\left(0,17 \mathrm{~km}^{2}\right)$, enquanto as demais são de Uso Sustentável, sendo elas a ARIE Federal Mata de Santa Genebra, a APA Estadual Represa do Bairro da Usina, a APA Estadual Sistema Cantareira, a APA Estadual Fernão Dias, a APA Estadual Piracicaba e Juqueri Mirim Área II e a APA Municipal Sousas e Joaquim Egídio.

Outro tipo de área protegida identificado são as APP's, que ocupam $433,74 \mathrm{~km}^{2}$, ou $15 \%$ da área total da bacia. Com esse valor, pode-se dizer que as áreas protegidas abrangem uma porção significativa do território onde, somando-se as APPs e as UCs, tem-se que 1.783,16 $\mathrm{km}^{2}$ da área da bacia do Rio Atibaia encontra-se sob algum tipo de proteção legal. Ressalta-se que isto não significa que essas áreas estejam efetivamente preservadas, apenas que sua proteção está amparada em aspectos legais. Uma vez amparadas legalmente, as UCs devem ser efetivamente implementadas através de ferramentas de gestão apontadas pela Lei do Sistema Nacional de Unidades de Conservação - SNUC (BRASIL, 2000), como a criação de um Órgão Gestor, um Conselho Gestor e um Plano de Manejo.

Já a Fragilidade Potencial é um reflexo das condições físicas naturais de instabilidade, resultantes da associação entre a fragilidade dos solos e o grau de dissecação do terreno, onde cabe-se mencionar como potencialmente frágeis áreas muito íngremes, planícies fluviais e fundos de vales. Mediante o cruzamento dessas informações, tem-se a Carta de Fragilidade Potencial da bacia. Pode-se observar que, nessa região, predominam áreas com Fragilidade Potencial Forte, que correspondem a $899,01 \mathrm{~km}^{2}$ e que representam cerca de $31 \%$ da área total. Somando-se esse valor ao total de áreas com Fragilidade Potencial Muito Forte, tem-se que $40 \%$ da área da bacia é potencialmente frágil (Tabela 7). 
Tabela 7 - Fragilidade Potencial da Bacia do Rio Atibaia.

\begin{tabular}{lcc}
\hline \multicolumn{1}{c}{ Fragilidade Potencial } & Área $\left.\mathbf{( k m}^{\mathbf{2}}\right)$ & $\mathbf{\%}$ \\
\hline Muito Fraca & 361,92 & 12,85 \\
Fraca & 744,77 & 26,44 \\
Média & 580,85 & 20,62 \\
Forte & 899,01 & 31,92 \\
Muito Forte & 229,85 & 8,16 \\
\hline
\end{tabular}

Fonte: Elaborado pelo autor.

O uso das terras, de acordo com o grau de proteção que oferece ao solo, determina a Fragilidade Ambiental de cada local. Observou-se que 50,52\% do território é utilizado para fins rurais, garantindo Média proteção ao solo. Usos representados por florestas nativas oferecem proteção Muito Alta ao solo e são importantes contribuintes para a redução da instabilidade da bacia. Destaca-se que apenas $0,24 \%$ do território possuem proteção Muito Baixa, nesse caso em decorrência de áreas onde o solo se encontra exposto.

Em relação à Fragilidade Ambiental diagnosticada, conforme Tabela 9, predominam na bacia áreas medianamente frágeis, que ocupam $951,67 \mathrm{~km}^{2}(33,79 \%)$. Áreas com Fragilidade Ambiental Muito Fraca e Fraca ocupam $617,28 \mathrm{~km}^{2}(21,92 \%)$ e $799,81 \mathrm{~km}^{2}$ (28,4\%). Juntas abrangem quase $50 \%$ da bacia. Já as áreas com Fragilidade Ambiental Forte e Muito Forte representam $447,64 \mathrm{~km}^{2}$ ou $15,89 \%$ da bacia.

Tabela 9 - Fragilidade Ambiental do Rio Atibaia

\begin{tabular}{lcc}
\hline Fragilidade Ambiental & Área $\left.\mathbf{( k m}^{\mathbf{2}}\right)$ & $\mathbf{\%}$ \\
\hline Muito Fraca & 617,28 & 21,92 \\
Fraca & 799,81 & 28,4 \\
Média & 951,67 & 33,79 \\
Forte & 354,84 & 12,6 \\
Muito Forte & 92,8 & 3,29 \\
\hline
\end{tabular}

Fonte:Elaborado pelo autor.

\section{Considerações finais}

A análise dos resultados obtidos no diagnóstico ambiental permite concluir que, apesar de relativamente pouco urbanizada, a Bacia Hidrográfica do Rio Atibaia encontra-se em processo de degradação ambiental.

Contribuem para esse quadro, além do alto grau de intervenção antrópica na bacia, principalmente nas APPs, os elevados valores de consumo de água e os despejos de efluentes domésticos, que promovem a deterioração dos corpos d'água.

É imprescindível, portanto, a adoção de medidas de recuperação das áreas degradadas na bacia e, para isso, deve-se priorizar duas frentes de trabalho. A primeira, trata da recuperação da vegetação em APPs, fator esse que contribui ainda para a proteção dos corpos d'água e para o incremento da conectividade entre remanescentes florestais nativos. Outra medida é a redução da instabilidade decorrente de áreas com Fragilidade Ambiental, as quais favorecem a ocorrência de movimentos degradacionais. 


\section{Referências}

Bernhardsen, T. Geographic Information Systems: An introduction. Arendal: Viak IT, 1992. 318p.

BRASIL. Lei no 9.433, de 08 de janeiro de 1965. Institui o novo Código Florestal Brasileiro.

BRASIL. Lei n⿳ 9.985, de 18 de julho de 2000. Cria o Sistema Nacional de Unidades de Conservação SNUC.

Câmara, G.; Queiroz, G. R. Arquitetura de Sistemas de Informação Geográfica. In: Câmara, G.; Davis, C.; Monteiro, A. M. V. (Org.). Introdução à Ciência da Geoinformação. São José dos Campos: INPE, 2001.

CNRBMA (Conselho Nacional da Reserva da Biosfera da Mata Atlântica) \& SOSMA (Fundação S.O.S. Mata Atlântica). Águas e Florestas da Mata Atlântica: por uma gestão integrada. Programa Águas e Florestas da Mata Atlântica. São Paulo, 2003. 43 p.

Coelho, A. C. P.; Gontijo JR, W. C.; Cardoso Neto, A. Unidades de planejamento e gestão de recursos hídricos: uma proposta metodológica. In: 7. ${ }^{\circ}$ SILUSBA - Simpósio de Hidráulica e Recursos Hídricos dos países de Língua Oficial Portuguesa, 2005, Évora. Anais. 7. ${ }^{\circ}$ SILUSBA, 2005.

Conforti, T. B.; Laurentis, G. L.; Adami, S. A conservação da biodiversidade na Região Metropolitana de Campinas. Resumo. In: 60 a Reunião Anual da SBPC. Campinas, 2008.

Duarte Neto, E. Gestão integrada dos recursos hídricos: saneamento básico na área metropolitana da subbacia do Rio Atibaia. 2005. 154 p. Dissertação (Mestrado). Universidade Estadual de Campinas. Campinas, 2005.

Fidalgo, E. C. C. Critérios para a análise de métodos e indicadores ambientais usados na etapa de diagnóstico de planejamentos ambientais. 2003. 258 p. Tese (Doutorado). Faculdade de Engenharia Agrícola - Universidade Estadual de Campinas. Campinas, 2003.

Ganzeli, J. P. Aspectos ambientais do planejamento dos recursos hídricos: a Bacia do Rio Piracicaba. In: TaukTornisielo, S. M. (Org.); Gobbi, N. (Org.); Fowler, H. G. (Org.). Análise Ambiental: Uma Visão Multidisciplinar. 2. ed. São Paulo. EDUNESP, 1995. pp. 134-140.

IBGE - Instituto Brasileiro de Geografia e Estatística. Cartas do Brasil. 1983. Escala 1:50.000.

IRRIGART - Engenharia e Consultoria em Recursos Hídricos. Bacias hidrográficas dos rios Piracicaba, Capivari e Jundiaí: Situação dos Recursos Hídricos 2002/2003. Relatório Final. Piracicaba: FEHIDRO/PCJ/CBH-PCJ, 2004.

IRRIGART - Engenharia e Consultoria em Recursos Hídricos. Bacias hidrográficas dos rios Piracicaba, Capivari e Jundiaí: Situação dos Recursos Hídricos 2004/2006. Relatório Síntese. Piracicaba: FEHIDRO/PCJ/CBH-PCJ, 2007. 75 p.

Longley, P. A.; Goodchild, M. F.; Maguire, D. J.; Rhind, D. W. Geographic Information Systems and Science. 2nd ed. New York: Wiley, 1999. 454p.

Macedo, R. K. de. A importância da avaliação ambiental. In: Tauk-Tornisielo, S. M. (Org.); Gobbi, N. (Org.); Fowler, H. G. (Org.). Análise Ambiental: Uma Visão Multidisciplinar. 2. ed. São Paulo. EDUNESP, 1995. p. 13-32.

Oliveira, J. B.; Camargo, M. N.; Rossi, M.; Calderano Filho, B. Mapa pedológico do Estado de São Paulo. Instituto Agronômico de Campinas/EMBRAPA Solos. Campinas, 1999.

Ross, J. L. S. Análise Empírica da Fragilidade dos Ambientes Naturais e Antropizados. Revista do Departamento de Geografia. São Paulo: FFLCH-USP, no 8, pp. 63-74. 1994.

Ross, J. L. S. Geomorfologia: ambiente e planejamento. $8^{\mathrm{a}}$ ed. São Paulo: Contexto, 2007. 85p.

Santos, R. F. Planejamento Ambiental: teoria e prática. São Paulo: Oficina de Textos, 2004. 184 p.

Santos, R. F.; Thomaziello, S.; Weill, M. A. M. Planejamento da Paisagem. In: Santos, R. F. (Org.). Vulnerabilidade Ambiental. Brasília: MMA, 2007. 192 p.

Tricart, J. Ecodinâmica. Rio de Janeiro: IBGE/SUPREN, 1977. 91p.

Tundisi, J. G. Água no século XXI: Enfrentando a escassez. São Carlos: RiMa, IIE, 2003. 248p.

Whately, M. Cantareira 2006 : um olhar sobre o maior manancial de água da Região Metropolitana de São Paulo. São Paulo : Instituto Socioambiental, 2007. 68p. 